\title{
Nanocomposite Nanofibers of Polyacrylonitrile (PAN) and Silver Nanoparticles (AgNPs) Electrospun from Dimethylsulfoxide
}

\author{
Nesrin DEMIRSOY ${ }^{1}$, Nuray UCAR ${ }^{2}$, Aysen ONEN $^{3}$, Nuray KIZILDAG ${ }^{2}$ \\ ${ }^{1}$ Istanbul Technical University, Polymer Science and Technology, Istanbul, Turkey. \\ ${ }^{2}$ Istanbul Technical University, Department of Textile Engineering, Istanbul, Turkey. \\ ${ }^{3}$ Istanbul Technical University, Department of Chemistry, Istanbul, Turkey.
}

\begin{abstract}
In this study, DMSO was used as the solvent and composite nanofibers of PAN with 1 and 3w\% AgNO3 content were electrospun. Then silver nanoparticles were in situ synthesized by chemical reduction. The effect of silver nitrate amount on the morphology, conductivity and mechanical properties of PAN/AgNPs composite nanofibers were investigated. Beadless and uniform composite nanofibers, the diameters of which were in the $499-515 \mathrm{~nm}$ range, were successfully electrospun. The breaking stress and breaking elongation of PAN/Ag composite nanofibers were higher than the neat PAN nanofibers. The conductivity was improved to around $10-8 \mathrm{~S} / \mathrm{cm}$ with the incorporation silver nanoparticles.
\end{abstract}

Keywords: Conductive, electrospinning, nanocomposite, nanofiber, polyacrylonitrile, silver nanoparticles.

\section{INTRODUCTION}

Polymer composites containing metal nanoparticles have attracted great attention because of their unique optical, electrical, and catalytic properties. The properties of these nanocomposites strongly depend on the amount, size and dispersion quality of the metal nanoparticles [1]. The mechanical mixing of metal nanoparticles into the polymer solution is an easy method with the disadvantage of agglomeration of the particles [2]. Recently in situ synthesis of metal nanoparticles has attracted more attention. Silver nanoparticles can be synthesized in polymers using many different methods such as photo reduction, heat treatment, chemical reduction using aqueous solution of sodium borohydride and hydrazinium hydroxide [3-6].

In literature, there are many studies about the synthesis of silver nanoparticles in polyacrylonitrile in many of which $\mathrm{N}, \mathrm{N}$-dimethylformamide (DMF) is used as the solvent [36] due to its ability to reduce Ag ions to the metallic silver even at room temperature without the use of any external reducing agent [1]. In this study, DMSO was used as the solvent and composite nanofibers of PAN with 1 and $3 \mathrm{w} \%$ $\mathrm{AgNO} 3$ content were electrospun. Then silver nanoparticles were in situ synthesized by chemical reduction. The effect of silver nitrate amount on the morphology, conductivity and mechanical properties of PAN/AgNPs composite nanofibers were investigated. Beadless and uniform composite nanofibers, the diameters of which were in the 499-515 nm range, were successfully electrospun. The breaking stress and breaking elongation of PAN/Ag composite nanofibers were higher than the neat PAN nanofibers. The conductivity was improved to around $10-8 \mathrm{~S} / \mathrm{cm}$ with the incorporation silver nanoparticles.

\section{MATERIALS AND METHOD}

\subsection{Materials}

Polyacrylonitrile (PAN) (Sigma Aldrich, 181315, average Mw: $150.000 \mathrm{~g} / \mathrm{mol})$, silver nitrate $(\mathrm{AgNO} 3$, Alfa Aesar Premion, 10858) and dimethylsulfoxide (DMSO) were used as received.

\subsection{Methods}

\subsubsection{Preparation of the solutions}

$1 \mathrm{w} \%$ and $3 \mathrm{w} \% \mathrm{AgNO} 3$ (with respect to the weight of PAN) were added to the required amount of DMSO and homogenized with ultrasonic tip for 10 minutes and with ultrasonic bath for $45 \mathrm{~min}$. Then PAN was added to the dispersion. Magnetic stirrer was used to mix the solution

Corresponding Author: Nuray KIZILDAG, Tel: +90 (212) 28561 83, E-mail: kizildagn@itu.edu.tr

Submitted: 15 October 2014, Revised: 04 March 2015, Accepted: 01 July 2015 
at $40^{\circ} \mathrm{C}$ for 3 hours. The concentration of PAN was kept constant as $7 \mathrm{w} \%$.

\subsubsection{Electrospinning}

Electrospinning was performed using equipment in which a horizontal electric field was generated between the nozzle and the rotating collector. It contained syringe pump and a grounded rotating collector. The electrospinning solution was fed using a syringe of $10 \mathrm{~mL}$ through a capillary tip with a diameter of $1.25 \mathrm{~mm}$. A high voltage power supply (0-50 $\mathrm{kV}$ ) was used to apply a voltage of $15 \mathrm{kV}$ and a syringe pump was used to feed the electrospinning solution at a constant rate of $1 \mathrm{~mL} / \mathrm{h}$. The distance between the nozzle and the collector was set as $10 \mathrm{~cm}$.

\subsubsection{In-situ synthesis of silver nanoparticles}

Chemical reduction process using hydrazinium hydroxide was applied for the in-situ synthesis of silver nanoparticles. For this, piece of the as-spun nanowebs was immersed into the aqueous solution of hydrazinium hydroxide (1:20 hydrazinium hydroxide: distilled water) for $30 \mathrm{~min}$ at room temperature, then washed with $100 \mathrm{~mL}$ distilled water two times and dried in room temperature to obtain composite nanofibers containing Ag nanoparticles.

\subsubsection{Characterization}

Scanning electron microscopy (SEM; EVO MA 10) was used to take the images of pure PAN and composite nanowebs. The diameters of at least 50 randomly selected nanofibers were measured using Image Analysis Software. Mechanical properties of the nanowebs were measured using a tensile tester with a $100 \mathrm{~N}$ load cell at a crosshead speed of $20 \mathrm{~mm} /$ min. The specimens were cut as $35 \mathrm{~mm}$ in length and $5 \mathrm{~mm}$ in width. The gage length was $15 \mathrm{~mm}$. The thicknesses of the specimens were measured with a Mitutoyo digital micrometre. Resistance measurements were performed using a two-probe system connected to Microtest 6370 LCR meter with a four-wire system and conductivity in $\mathrm{S} / \mathrm{cm}$ was calculated using the volume resistance value measured and the geometric dimensions of the samples.

\section{RESULTS AND DISCUSSION}

\subsection{Morphology}

The SEM images of the pure PAN and composite nanowebs taken with 10.0kX magnification can be seen in Figure 1.

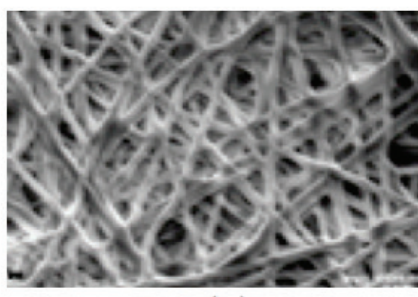

(a)

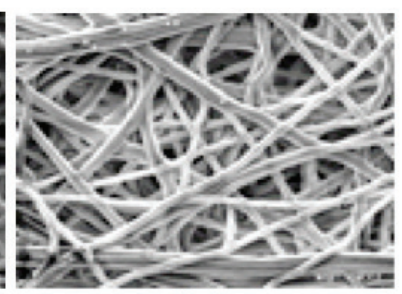

(b)

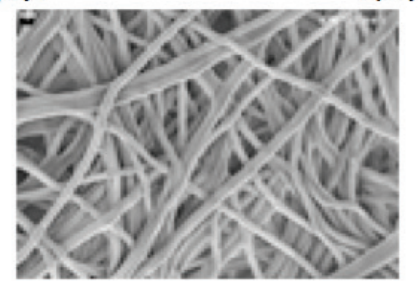

(c)

Figure 1. SEM images of (a) pure $\mathrm{PAN}$, (b) $1 \mathrm{w} \% \mathrm{AgNO}_{3} /$ $\mathrm{PAN},(\mathrm{c}) 3 \mathrm{w} \% \mathrm{AgNO}_{3} / \mathrm{PAN}$ nanowebs.

The nanofibers had uniform structures. On addition of AgNO3 and application of the reduction process, the average diameter of the nanofibers didn't change significantly at AgNO3 contents of 1 and $3 \mathrm{w} \%$. While the diameter of pure PAN nanofibers was $515.34 \mathrm{~nm}, 1 \mathrm{w} \%$ and $3 \mathrm{w} \%$ AgNO3 addition followed by the chemical reduction process resulted in diameters of $499 \mathrm{~nm}$ and $514 \mathrm{~nm}$, respectively. The additions of nanoparticles are expected to result in an increase in nanofiber diameter due to the increase in solution viscosity. On the other hand, the chemical reduction process is observed to result in a decrease in nanofiber diameter while the increase in net charge density is known to have thinning effect. The combination of all these factors resulted in a compensation in nanofiber diameter for the $\mathrm{AgNO} 3$ contents of $1 \mathrm{w} \%$ and $3 \mathrm{w} \%$ and no significant variation was observed in nanofiber diameter.

\subsection{Mechanical Properties}

Table 1 shows the mechanical properties of pure PAN and nanocomposite nanofibers containing AgNPs.

Table 1. Mechanical properties of composite nanofibers.

\begin{tabular}{cccc}
\hline Samples & $\begin{array}{c}\text { Breaking } \\
\text { Strength } \\
(\mathrm{MPa})\end{array}$ & $\begin{array}{c}\text { Breaking } \\
\text { Elongation } \\
(\%)\end{array}$ & $\begin{array}{c}\text { E-modulus } \\
(\mathrm{MPa})\end{array}$ \\
PAN-DMSO & 8.64 & 8.95 & 100.59 \\
$1 \mathrm{w} \% \mathrm{AgNO}_{3} / \mathrm{PAN}$ (reduced) & 13.81 & 36.41 & 73.00 \\
$3 \mathrm{w} \% \mathrm{AgNO}_{3} / \mathrm{PAN}$ (reduced) & 11.24 & 18.69 & 39.23 \\
\hline
\end{tabular}


The breaking strength and breaking elongation values increased with addition of $1 \mathrm{w} \% \mathrm{AgNO}_{3}$ and then decreased with the increase in $\mathrm{AgNO}_{3}$ content from $1 \mathrm{w} \%$ to $3 \mathrm{w} \%$ still being higher than the pure PAN nanoweb. The improvements in the breaking strength and the breaking elongation were attributed to the increased compactness of the nanoweb as a result of the chemical reduction process. Besides; the nanosilver as an inorganic filler material might have had a positive effect on the breaking strength. The decrease in breaking strength with the increase in the additive amount might have been due to the agglomeration of the nanoparticles. There was a decrease in E-modulus values which showed that stiffness of the nanoweb decreased with the addition of $\mathrm{AgNO}_{3}$ and subsequent reduction process.

\subsection{Conductivity}

Table 2 shows the conductivity values of nanocomposite nanofibers produced with the addition of AgNPs.

Table 2. Conductivity values of nanocomposite nanofibers.

\begin{tabular}{cccc}
\hline Samples & $\begin{array}{c}\text { Conductivity } \\
\text { S/cm }\end{array}$ & Standard deviation & $\begin{array}{c}\text { Coefficient } \\
\text { of variation }\end{array}$ \\
$\begin{array}{c}1 \mathrm{w} \% \mathrm{AgNO}_{3} / \\
\mathrm{PAN}\end{array}$ & $4.56 * 10^{-8}$ & $1.53 * 10^{-8}$ & 33.5 \\
$\begin{array}{c}3 \mathrm{w} \% \mathrm{AgNO}_{3} / \\
\mathrm{PAN}\end{array}$ & $3.79 * 10^{-8}$ & $1.12^{-8} 10^{-10}$ & 29.6 \\
\hline
\end{tabular}

Pure PAN nanoweb has a reported conductivity value of 10-12 S/cm [7]. The in-situ synthesis of silver nanoparticles resulted in an increase in the conductivity of PAN nanofibers. The conductivity was measured as $10-8 \mathrm{~S} / \mathrm{cm}$ for the composite nanowebs produced. With the conductivity of $10-8 \mathrm{~S} / \mathrm{cm}$, they can be utilized in antistatic applications [8].

\section{CONCLUSION}

Polyacrylonitrile nanofibers with $\mathrm{AgNO} 3$ from electrospinning solutions prepared with DMSO were successfully electrospun at the loadings of 1 and $3 w \%$. It was demonstrated in this study that dimethylsulfoxide was a suitable solvent for the production of PAN/AgNPs nanowebs. While the diameter of the nanofibers didn't change significantly with addition of $\mathrm{AgNO} 3$ followed by the chemical reduction process at loadings of $1 \mathrm{w} \%$ and $3 \mathrm{w} \%$, the mechanical properties improved with the addition of $1 \mathrm{w} \% \mathrm{AgNO} 3$. Increase in the content of $\mathrm{AgNO} 3$ resulted in a decrease in breaking strength and breaking elongation while they were still higher than the mechanical properties of pure polyacrylonitrile nanoweb. The composite nanowebs showed a conductivity on the order of $10-8 \mathrm{~S} / \mathrm{cm}$ which was in the suitable range for antistatic applications. It was concluded that $\mathrm{AgNO} 3$ could be used as a filler developing antibacterial properties while improving both mechanical and electrical properties.

\section{ACKNOWLEDGEMENT}

We would like to thank to TUBITAK for supporting this study with Project (112M877).

\section{REFERENCES}

[1] Mahapatra, A., Garg, N., Nayak, B.P., Mishra, B.G., Hota, G., Studies on the Synthesis of Electrospun PAN-Ag Composite Nanofibers for Antibacterial Application, Journal of Applied Polymer Science, Vol. 124, 1178-1185, 2012.

[2] Sichani, G.N., Morshed, M., Amirnasr, M., Abedi, D., In Situ Preparation, Electrospinning, and Characterization of Polyacrylonitrile Nanofibers Containing Silver Nanoparticles, Journal of Applied Polymer Science, 116, 1021-1029, 2010.

[3] Chaloupka K., Malam, K., Seifalian, A. Y., Nanosilver as a New Generation of Nanoproduct in Biomedical Applications, Trends in Biotechnology, 28, 11, 2010.

[4] Wang, Y., Yang, Q., Shan, G., Wang, C., Du, J., Wang, S., Li, Y., Chen, X., Jing, X., Wei, Y., Preparation of silver nanoparticles dispersed in polyacrylonitrile nanofiber film spun by electrospinning, Materials Letters, 59, 3046-3049, 2005.

[5] Rujitanaroj, P., Pimpha, N., Supaphol, P., Preparation, Characterization, and Antibacterial Properties of Electrospun Polyacrylonitrile Fibrous Membranes Containing Silver Nanoparticles, Journal of Applied Polymer Science, 116, 1967-1976, 2010.

[6] Bai, J., Yang, Q., Wang, S., Li, Y., Preparation and characterization of electrospun $\mathrm{Ag} /$ polyacrylonitrile composite nanofibers, Korean J. Chem. Eng., 28(8), 1761-1763, 2011.

[7] Almuhamed N, Khenoussi L, Schacher D, Adolphe HB, Measuring of Electrical Properties of MWNTReinforced PAN Nanocomposites, Journal of Nanomaterials, 2012, 1-7.

[8] Saini P, Choudhary V, Electrostatic charge dissipation and electromagnetic interference shielding response of polyaniline based conducting fabrics, Indian Journal of Pure Applied Physics, 2013, 51, 112-117. 